\title{
A Systematic Approach to Explorative Scenario Analysis in Emergy Assessment with Emphasis on Resilience
}

\author{
Andreas Kamp ${ }^{1} \cdot$ Hanne Østergård ${ }^{1}$
}

Received: 18 March 2016/Accepted: 2 July 2016/Published online: 3 August 2016

(c) Springer International Publishing Switzerland 2016

\begin{abstract}
Fossil energy depletion (specifically peak oil) and climate change are imagined to profoundly affect human civilisation. This motivates assessment of resilience, a concept associated with the ability to persist and maintain function. Explorative scenarios may be used to cast light on what the future may bring. We develop a systematic approach to explorative scenario analysis and attempt to quantify aspects of resilience specifically for emergy assessment (EmA) of production systems. We group system inputs into five categories: (1) fossil fuels, their derivatives, metals and minerals, (2) on-site renewable inputs, (3) slowly renewable inputs, (4) direct labour and (5) indirect labour. We consider the existing EmA indicators of biophysical efficiency (the unit emergy value, UEV), the degree of dependence on free, renewable, natural flows of energy $(\% R)$ and the degree of dependence on local inputs (\%Local) as relevant resilience indicators in EmA. Formulas to calculate the corresponding indicators for the outputs in future scenarios are provided, e.g. the resulting adjustment factor for the UEV. We demonstrate our approach by parameterising four conceivable energy descent scenarios described by corresponding narratives. We analyse the aggregated effect on UEVs of these scenarios for production systems that differ with respect to how the emergy flow is distributed among the five input categories. We find that for most production systems,
\end{abstract}

Hanne Østergård

haqs@kt.dtu.dk

Andreas Kamp

ankam@kt.dtu.dk

1 Department of Chemical and Biochemical Engineering, Technical University of Denmark, DTU, 2800 Kgs. Lyngby, Denmark scenario conditions significantly affect the UEV. The production systems that rely primarily on on-site renewable resources appear less sensitive to societal changes. The significance of labour inputs varies among scenarios, and a higher percentage of labour inputs leads to increasing UEV in a Green Tech scenario but lower UEV in more radical energy decent scenarios. A comparison of two specific production systems showed that different expectations of the future lead to contrasting conclusions regarding prioritisation. We use the insight gained in the study to suggest venues for sustainable development under changing societal conditions.

Keywords Explorative scenario - Resilience - Emergy · Sustainability assessment $\cdot$ Future

\section{Introduction}

Environmental sustainability assessment (ESA) based on life cycle assessment (LCA) (EC 2010), emergy assessment (EmA) (Odum 1996) and other quantitative techniques may be used to support strategic planning and prioritisation in the face of larger societal and environmental changes. All ESA methods face the challenge of not knowing the future scenarios in which the assessed activities take place and the related environmental effects occur. Timescale issues, therefore, arise when assessments are used for making strategic, long-term decisions, but so far, modelling that includes the possible effects of larger societal and environmental changes are nearly absent from LCA and EmA. EmA is an environmental accounting method for the study of resource use. The systematic inclusion of work done by nature and human labour inputs 
make EmA particularly interesting in the study of effects of resource scarcity and altered living standards.

Concern over a "peak" in the production of fossil energy (Hirsch 2008; Lambert and Lambert 2011; Tverberg 2012; Mohr et al. 2015), the consequences of significant climatic changes (Nordås and Gleditsch 2007; Schubert et al. 2007; IPCC 2014) and the possible social and political implications of these phenomena lead to believe that decision-making focussing on single changes in societal conditions or extrapolating previous development is increasingly inadequate.

Explorative scenario modelling is a useful approach to analyse uncertainty in studies of systems or technologies that may be expected to function in the medium- to longterm future. Börjeson et al. (2006) identify explorative scenarios with the question "what can happen?", distinguishing it from predictive scenarios ("what will happen") and normative scenarios ("how can a specific target be reached"). Explorative scenarios aim to explore the future from various perspectives, focusing on profound changes and a relatively long-time horizon (Höjer et al. 2008). Explorative scenario analyses are characterised by considering multiple futures based on system thinking (Spielmann et al. 2005). The typical selection of a variety of fundamentally different scenarios highlights that societal development can go in several directions, exposing the study results to a broad range of possible influences. System thinking represents the view that complex systems are internally linked in myriad ways and influence each other nonlinearly and with strong reciprocal feedbacks, making it impossible to isolate the effect of, for example, oil prices, on fertiliser or food prices.

Qualitative explorative scenarios are widely used, e.g. as narratives or storylines. However, actual modelling of environmental sustainability based on the quantification of explorative scenario characteristics has been demonstrated in only a few cases. Spielmann et al. (2005) explore four scenarios for regional transport based on altering specific unit processes from the LCA database ecoinvent 2000. The effect on transport technologies of socio-economic variables is quantified using "educated estimates" of changed greenhouse gas and NOx emissions. Results are used to rank transport alternatives under different future conditions. Fortes et al. (2015) link socio-economic storylines to energy modelling on a national level for Portugal. Determination of growth rates of socio-economic indicators (e.g. GDP, population, economic growth of certain energy-intensive sectors) is supported by "experts' best guess judgment" of the chosen scenario narratives. The result is the identification of the most cost-effective set of energy technologies and the associated greenhouse gas emission trajectories for each scenario. The lack of development of explorative scenarios in LCA and EmA is problematic if we want to use these tools to prioritise policies and technologies that entail resource use and emissions occurring in the future. The use of explorative scenarios may clarify conceivable developments and lead to an improved understanding of the possible consequences of our decisions.

Resilience for social-ecological systems has been defined as "the capacity of a system to absorb disturbance and reorganise while undergoing change so as to still retain essentially the same function, structure, identity and feedbacks" (Walker et al. 2004). An additional definition is provided by Kupers (2014): "Resilience is the capacity of business, economic and social structures to survive, adapt and grow in the face of change and uncertainty related to disturbances, whether they be caused by resource stresses, societal stresses and/or acute events". Carpenter et al. (2001) attempt to concretise resilience by distinguishing between specified and general resilience. The provided definitions relate to general resilience, while specified resilience poses the question "resilience of what to what?"

Resilience is often mentioned as a prerequisite for sustainable development, and much effort has been put into developing quantifiable resilience indicators that may help to understand resilience dynamics and simplify decisionmaking. Walker et al. (2004) show that selected state variables determine the position of a system in a state space with basins of attraction. The depth and width of a basin where a system is located, and the distance to the basin's edge are suggested to quantify resilience. The approach is complex to use in practice without extraordinary data modelling (Carpenter 2001). Carpenter et al. (2001) use the adaptive cycle (Holling 1986) as starting point and associate several influential indicators with the distinct phases of the cycle, e.g. surrounding soil phosphorus and stock density as resilience indicators of a lake's clear-water state to a short-term increase in phosphorus input due to weather or human influence. However, the indicators proposed by Carpenter et al. (2001) are case specific and build on meticulous, long-term study of detailed societal-ecological relationships. Cabell and Oelofse (2012) argue that because of its complexity, resilience of agroecosystems defies measurement. However, based on an extensive review, Cabell and Oelofse do compile rules of thumb that may be used to assess resilience in agroecosystems. As an alternative to estimate resilience directly, Bennett et al. (2005) suggest to monitor quantifiable attributes of systems that are related to resilience. At this point, however, no simple resilience indicator is available for screening of production systems that are particularly sensitive to specified changes on a societal level.

The remainder of this article can be divided into three parts: At first, we develop a systematic approach to explorative scenario analysis in EmA. In preparation of this, we introduce the EmA method more thoroughly and 
propose to consider three existing emergy indicators as indicative of resilience. Then, we demonstrate our approach to explorative scenario analysis by constructing four energy descent scenarios. To exemplify the analytical potential of the approach, we examine the specific importance of human labour inputs in these scenarios. Finally, we discuss the applicability and limitations of resilience indicators and explorative scenario analysis and use the insight gained in the study to suggest venues for sustainable development under changing societal conditions.

\section{Materials and Methods}

\section{Emergy Assessment}

EmA is an embodied energy analysis method founded in thermodynamics. Emergy is defined as the solar energy required, directly and indirectly, to make a product or service (Odum 1996). All forms of energy, materials and human labour that contribute, directly or indirectly, to a production process are evaluated using the common emergy unit of solar emergy joules (sej). The valuation of materials, energy carriers and human labour, based on accumulated energy dissipation, has been referred to as "biosphere currency" (Franzese et al. 2009). The valuation of human labour in natural resource terms implies considering humans and human activity as a part of, rather than apart from, nature. EmA has been used to emphasise the interplay between the natural resource base of economic production and human development (Odum and Odum 2006; Abel 2010; Brown and Ulgiati 2011). The inclusion in EmA of natural, human and social capital in the production of economic assets provides a framework for studying the implications of changes on a societal scale.

\section{EmA Indicators}

In EmA practice, the conversion of physical quantities to emergy is done by multiplication with unit emergy values (UEVs), where the UEV is the emergy per unit (e.g. sej/J, sej/ $\mathrm{g}$, sej/man-hour). Converting all inputs to a common unit (sej) makes EmA a strong analytical tool able to calculate a range of sustainability indicators, including the UEV and the renewability fraction (for an extensive list, see Brown and Ulgiati 1997). The UEV (=emergy of inputs/energy of outputs) indicates biophysical efficiency, and a high UEV is indicative of large, accumulated energy losses in the creation, extraction, transport, design, manufacture, etc. per unit of a given output. In comparisons of systems that yield similar outputs, a relatively low UEV points to superior biophysical efficiency. The renewability fraction $(\% R=R /$
$R+N+F$ ) is found by the routine categorisation of inputs based on source as either on-site renewable resources $(R)$, on-site non-renewable resources $(N)$ or feedbacks from society $(F)$, i.e. external inputs. External inputs $(F)$ may also be evaluated based on their respective $R-N-F$ profile (Ulgiati et al. 2005; Cavalett et al. 2006) and provide information for the calculation of the global renewability fraction $\left(\% R_{\text {global }}\right)$. It has recently been suggested to evaluate systems based on the location of inputs to emphasise the embeddedness of a system in its immediately surrounding system (Wright and Østergård 2015). The local supply fraction (\%Local) for a system and its outputs is estimated as the weighted average of the local supply fraction of all required inputs. The categorisation of inputs as local resources is based on knowledge of the relevant supply chains.

\section{Quantitative Resilience Indicators Based on Emergy Indicators}

Following the suggestion by Bennet et al. (2005) to monitor quantifiable system attributes that are related to resilience, we suggest three existing emergy indicators to assess resilience, based on the following reasoning. We suggest to consider biophysical efficiency (UEV) as a resilience indicator because systems that make efficient use of available resources can be expected to outlast those that carry out comparable functions less efficiently. We suggest to consider the global renewability fraction $\left(\% R_{\text {global }}\right)$ as a resilience indicator because renewable resources are by definition available indefinitely. In an era of rapid depletion of non-renewable resources, a high global renewability fraction reduces the risk of system failure caused by supply unavailability. We suggest to consider the local supply fraction (\%Local) as an indicator for autonomy, i.e. to indicate the level of access to and control over direct inputs. This implies that the farther away inputs originate, the less autonomous the system is. The local supply fraction may be considered a resilience indicator because shorter supply chains can be expected to be less vulnerable to disruption by uncontrolled social factors and resource limits than longer supply chains. We interpret the indicators as supportive of resilience in a broader sense and suggest them as a contribution to the development of quantitative resilience indicators. Considered individually, each indicator is neither sufficient nor necessary for resilience but considered as a set, they may be useful in preliminary screening of production systems.

\section{Development of a Systematic Approach to Explorative Scenario Analysis in EmA}

A systematic approach to scenario analysis based on input categorisation and parameter adjustment to scenario conditions is presented. 
Explorative scenario analysis involves three steps: (1) define reference conditions and associated parameter values ("status quo"), (2) identify alternative scenarios and associated parameter values based on best knowledge, and (3) redo assessment with altered parameters.

At first, we describe how the three indicators of the output from the system are calculated from the corresponding indicators based on the inputs.

$\mathrm{UEV}(\mathrm{O})=\left(\sum I_{\mathrm{i}} * \mathrm{UEV}_{\mathrm{i}}\right) / \mathrm{O}$

for the biophysical efficiency (UEV) of production of output $\mathrm{O}$ from a system with $\mathrm{i}$ inputs of amount $I_{\mathrm{i}}$ and respective biophysical efficiencies $U_{E V}$ (in sej/unit),

$\% R_{\text {global }}(\mathrm{O})=\left(\sum \mathrm{Em}_{\mathrm{i}} * \% \boldsymbol{R}_{\text {global }, \mathrm{i}}\right) / \mathrm{Em}_{\mathrm{O}}$

for the global renewability fraction $\left(\% R_{\text {global }}\right)$ of output $\mathrm{O}$, where $\mathrm{Em}_{\mathrm{i}}=$ emergy flow of input $\mathrm{i}, \% R_{\text {global, } \mathrm{i}}$ is the global renewability fraction of input $i$, and $\mathrm{Em}_{\mathrm{O}}$ is the emergy of output $\mathrm{O}$, and

$\% \operatorname{Local}(\mathrm{O})=\left(\sum \operatorname{Em}_{\mathrm{i}} * \%\right.$ Local $\left._{\mathrm{i}}\right) / \mathrm{Em}_{\mathrm{O}}$

for the local supply fraction (\%Local) of output $\mathrm{O}$ with $\%$ Local $_{i}$ being the local supply fraction of input i. Absence of scenario specification for a variable indicates reference conditions.

For a simpler explanation of the approach, we group inputs into categories: on-site renewables (OR) being sun, wind, rain and deep earth heat; non-renewables (NR) being fossil fuels, their derivatives plastics, synthetic fertilisers, pesticides, metals and minerals; slowly renewables (SR) being biological material like wood and crops, including their residues; direct labour (DL), being applied labour; and indirect labour (IL), being labour embodied in external material and energy inputs (Fig. 1).

For category c (i.e. OR, NR, SR, DL or IL) and scenario $\mathrm{s}$, we consider the scenario-dependent input adjustment factors $\alpha_{\mathrm{c}, \mathrm{s}}$ for input quantity and $\beta_{\mathrm{c}, \mathrm{s}}$ for input UEVs. In a similar manner, we refer to the scenario-dependent global

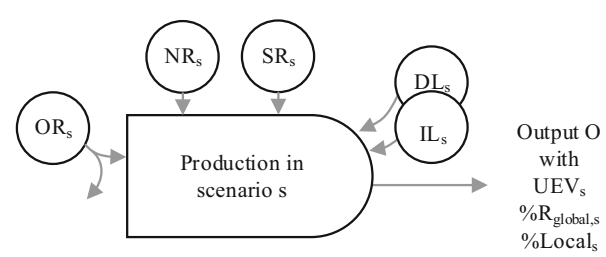

Fig. 1 Production of an output $\mathrm{O}$ relies on inputs that can be categorised as on-site renewable (OR), non-renewable (NR), slowly renewable (SR), direct labour (DL) and indirect labour (IL). Characteristics of the inputs and thereby the output change according to scenario s conditions renewability fractions $\% R_{\text {global,c,s }}$ and local supply fractions $\%$ Local $_{\mathrm{c}, \mathrm{s}}$.

Taking into account that UEVs, global renewability fractions and local supply fractions of inputs will differ between the different categories, the scenario parameterisation for the calculation of UEV, global renewability fraction and local supply fraction of output $\mathrm{O}$ under scenario s conditions for the five categories of inputs may be expressed as

$\mathrm{UEV}_{\mathrm{s}}(\mathrm{O})=\left(\sum I_{\mathrm{i}} * \alpha_{\mathrm{c}, \mathrm{s}} * \mathrm{UEV}_{\mathrm{i}} * \beta_{\mathrm{c}, \mathrm{s}}\right) / \mathrm{O}$

$\% R_{\text {global }, \mathrm{s}}(\mathrm{O})=\left(\sum \mathrm{Em}_{\mathrm{i}, \mathrm{s}} * \% R_{\text {global }, \mathrm{c}, \mathrm{s}}\right) / \mathrm{Em}_{\mathrm{O}, \mathrm{s}}$

${ }_{0} \operatorname{Local}_{\mathrm{s}}(\mathrm{O})=\left(\sum \mathrm{Em}_{\mathrm{i}, \mathrm{s}} * \% \operatorname{Local}_{\mathrm{c}, \mathrm{s}}\right) / \mathrm{Em}_{\mathrm{O}, \mathrm{s}}$

with $\mathrm{i}$ in category $\mathrm{c}(\mathrm{i} \in \mathrm{c})$. To be able to quantify the influence of different future scenarios on future values of $\mathrm{UEV}_{\mathrm{s}}$ of output from a specific production system in scenario $s$, an output adjustment factor for UEV in scenario s, $\lambda_{\mathrm{s}}$, is defined as follows assuming that the output $\mathrm{O}$ is kept constant between the reference and the future conditions.

$\lambda_{\mathrm{s}}=\mathrm{UEV}_{\mathrm{s}}(\mathrm{O}) / \mathrm{UEV}(\mathrm{O})$

Equation (4) may then be elaborated on, using that $\% \mathrm{Em}_{\mathrm{c}}$ equals the percentage of total emergy flow in category $\mathrm{c}$ under reference conditions, so that

$$
\begin{aligned}
\mathrm{UEV}_{\mathrm{s}}(\mathrm{O}) & =\left(\sum_{\mathrm{c}} \alpha_{\mathrm{c}, \mathrm{s}} * \beta_{\mathrm{c}, \mathrm{s}} * \sum_{\mathrm{i} \in \mathrm{c}}\left(I_{\mathrm{i}} * \mathrm{UEV}_{\mathrm{i}}\right)\right) / \mathrm{O} \\
& =\sum_{\mathrm{c}} \alpha_{\mathrm{c}, \mathrm{s}} * \beta_{\mathrm{c}, \mathrm{s}} * \% \operatorname{Em}_{\mathrm{c}} * \operatorname{UEV}(\mathrm{O})
\end{aligned}
$$

Furthermore, $\lambda_{\mathrm{s}}$ may be calculated using Eq. (8) as

$\lambda_{\mathrm{s}}=\sum_{\mathrm{c}} \alpha_{\mathrm{c}, \mathrm{s}} * \beta_{\mathrm{c}, \mathrm{s}} * \% \mathrm{Em}_{\mathrm{c}}$

Scenario-dependent input adjustment factors for $\% R_{\text {global,c,s }}$ and $\%$ Local $_{\mathrm{c}, \mathrm{s}}$ may be introduced to obtain output adjustment factors in the same manner as for the UEV.

\section{Results}

\section{Explorative Scenario Analysis Based on Four Conceivable Futures}

Reference scenario assumptions for a typical EmA evaluation of a production system are provided in Table 1. Four future scenarios Green Tech, Brown Tech, Earth Stewards and Lifeboats are constructed by altering the following parameters: (1) the amount of indirect labour which we consider indicative of the availability of purchased 
materials since the less available a material is, the more labour is necessary to acquire it, raising its price; (2) the UEVs of direct labour and indirect labour which we consider indicative of material standard of living (MSOL) since a higher MSOL is associated with more resources appropriated per unit of labour input; (3) the UEVs of materials that account for the resource use (material and energy inputs) to form, extract and process material inputs; (4) the global renewability fraction of inputs; and 5) the local supply fraction of inputs. Notice that the amount of indirect labour $\left(\alpha_{\mathrm{c}}\right)$ and the UEV of inputs $\left(\beta_{\mathrm{c}}\right)$ of the future scenarios relative to reference scenario are adjustment factors to multiply with reference indirect labour amounts and UEVs, respectively, while the global renewability fraction $\left(\% R_{\text {global,c,s }}\right)$ and local supply fraction $\left(\% \operatorname{Local}_{\mathrm{c}, \mathrm{s}}\right)$ of the future scenarios should be used instead of $\% R_{\text {global }}$ and \%Local.

Our parameterisation of the future scenarios is presented alongside reference conditions and will be explained as part of the narratives later. Inputs are categorised into five categories according to the description above. Reference conditions include a variety of inputs that are system specific and have individual UEVs (indicated by '_' in Table 1). Further, it is assumed for the reference conditions that the $\% R_{\text {global }}$ for inputs in category NR is no higher than $5 \%, 50 \%$ for SR inputs and $100 \%$ for OR by definition. For labour inputs, $\% R_{\text {global }}$ is assumed to be $16 \%$, equal to that of the global economy (Brown and Ulgiati 2011). Further, we assume that \%Local is $0 \%$ for NR, $50 \%$ for SR, $100 \%$ for DL and $0 \%$ for IL, and OR is $100 \%$ local by definition.

Input quantities generally remain fixed when performing the scenario analysis $\left(\alpha_{\mathrm{c}, \mathrm{s}}=100 \%\right)$. Adjusting input quantities implies using a different technology or in other ways altering the defining characteristics of a studied production system and this is not the aim. An exception is indirect labour. The increased indirect labour input in Brown Tech, Earth Stewards and Lifeboats reflects that external inputs are generally more difficult to obtain and thus require additional human labour inputs, e.g. in discovery, development, extraction, processing and transport of fuels, metals and water. Additional indirect material and energy inputs may also be required, e.g. more energy inputs to obtain oil, and this is reflected in higher UEVs.

Table 1 Modelling parameter values for inputs in emergy assessment under reference and four future scenario conditions

\begin{tabular}{|c|c|c|c|c|c|}
\hline & $\begin{array}{l}\text { Reference } \\
(\%)\end{array}$ & $\begin{array}{l}\text { Green Tech } \\
(\%)\end{array}$ & $\begin{array}{l}\text { Brown Tech } \\
(\%)\end{array}$ & $\begin{array}{l}\text { Earth Stewards } \\
(\%)\end{array}$ & $\begin{array}{l}\text { Lifeboats } \\
(\%)\end{array}$ \\
\hline \multicolumn{6}{|l|}{ Input quantity, relative to reference conditions $\left(\alpha_{c, s}\right)$} \\
\hline Amount of indirect labour (IL) & - & 100 & 150 & 200 & 500 \\
\hline \multicolumn{6}{|l|}{ UEV of inputs, relative to reference conditions $\left(\beta_{\mathrm{c}, \mathrm{s}}\right)$} \\
\hline Fossil fuels, their derivatives, metals, minerals (NR) & - & 50 & 200 & 200 & 300 \\
\hline On-site renewables (OR) & - & 100 & 100 & 100 & 100 \\
\hline Slowly renewables (SR) & - & 50 & 200 & 200 & 300 \\
\hline Direct labour (DL) and indirect labour (IL) & - & 200 & 50 & 50 & 10 \\
\hline \multicolumn{6}{|l|}{ Global renewability fraction $\left(\% R_{\text {global }, \mathrm{c}, \mathrm{s}}\right)$} \\
\hline Fossil fuels, their derivatives, metals, minerals (NR) & $5^{\mathrm{a}}$ & 50 & 1 & 100 & 50 \\
\hline On-site renewables $(\mathrm{OR})$ & $100^{\mathrm{b}}$ & 100 & 100 & 100 & 100 \\
\hline Slowly renewables (SR) & $50^{\mathrm{c}}$ & 100 & 1 & 100 & 100 \\
\hline Direct labour (DL) and indirect labour (IL) & $16^{\mathrm{d}}$ & 50 & 5 & 100 & 50 \\
\hline \multicolumn{6}{|l|}{ Local supply fraction $\left(\%\right.$ Local $\left._{\mathrm{c}, \mathrm{s}}\right)$} \\
\hline Fossil fuels, their derivatives, metals, minerals (NR) & $0^{\mathrm{c}}$ & 0 & 0 & 100 & 100 \\
\hline On-site renewables (OR) & $100^{\mathrm{b}}$ & 100 & 100 & 100 & 100 \\
\hline Slowly renewables (SR) & $50^{\mathrm{c}}$ & 50 & 10 & 100 & 100 \\
\hline Direct labour (DL) & $100^{\mathrm{c}}$ & 100 & 100 & 100 & 100 \\
\hline Indirect labour (IL) & $0^{\mathrm{c}}$ & 0 & 0 & 0 & 0 \\
\hline
\end{tabular}

For $\alpha$ and $\beta$, the parameter values are given as percentages of the reference values which vary within each category. Subscript $\mathrm{c}$ designates input category and subscript s designates scenario

${ }^{\text {a }}$ Cavalett et al. (2006)

${ }^{\mathrm{b}}$ By definition

c Assumption

${ }^{\mathrm{d}}$ Brown and Ulgiati (2011) 
The parameterisation of the explorative scenarios is based on narratives (see below). The perspective of the narratives is that changes in the natural resource base are considered to affect the production of economic assets that human development is based on (Fig. 2). The functioning of the economic system depends also on social institutions, representative of human development. These interlinkages are important for the functioning of a given production system (e.g. Fig. 1), making it relevant to include social dynamics in the development of scenarios. The narratives (Green Tech, Brown Tech, Earth Stewards and Lifeboats) are inspired by Heinberg (2004), Hopkins (2006) and Holmgren (2009). The parameterisation of societal development is the result of the authors' interpretation of these narratives.

\section{Green Tech}

In the Green Tech future, a significant part of the energy supply from fossil fuels is successfully replaced by renewable alternatives without major supply disturbances and social unrest. The relatively smooth transition and stabilisation is facilitated by increased efficiency in infrastructure production, energy conversion, storage and transport, and cultural acceptance through education and subsidisation. The success is primarily attributed to political leadership and cooperation, technological breakthroughs, vigorous engagement by for-profit and not-forprofit organisations and the popular support of large groups of citizens demanding a proactive approach to planetary boundary-related problems, including climate change. After a period of structural reorganisation of political and financial markets (in the form of minor bubbles and collapses), a new era of economic growth begins that is decoupled from growth in resource use. The characteristics of this future are low-cost and renewable energy supply, sustainable use of renewable and slowly renewable materials, strategic use of fossil fuels and other non-renewables with careful recycling, and increased but environmentally conscious consumption.

The Green Tech narrative imagines higher renewability of inputs, less resource use per material and purchased energy input, i.e. increased efficiency, increased material standard of living (MSOL) reflected in higher resource use per labour input, and autonomy similar to reference. The Green Tech scenario assumes lower UEVs for non- and slowly renewable resources (50\% of reference conditions) and higher UEVs of labour (200\%, i.e. a higher MSOL) based on increased efficiency. Global renewability fractions are assumed to increase for non-renewables (to $50 \%$ ), slowly renewables (to $100 \%$ ) and labour (to $50 \%$ ) based on substitution of renewable inputs for non-renewable inputs. Autonomy (\%Local) is assumed similar to reference.

\section{Brown Tech}

In the Brown Tech world, the demand for energy outruns the development and establishment of renewable energy technologies. The pressure for economic growth leads to removal of environmental taxation and subsidisation schemes, attempts to increase consumption, and emphasis on centralised, large-scale energy supply, factory-scale biofuels and food production typically managed by states or large corporations. For some time, this secures some growth and the supply of most goods, albeit at a higher cost and, in general, based on non- or slowly renewable resources like unconventional oil and gas, synthetic fertiliser, top soil and forests with increasing inputs per output. The result is increased dependence on fossil and nuclear fuels, at an increasing cost, and deterioration of social, economic and political institutions involving social
Fig. 2 Production of goods and services (economic assets) relies on natural resources as well as human and social resources. Changes in the natural resource base influence human development in terms of population and social institutions which provide feedback to production. The production and management of slowly renewable resources is affected by changes in social institutions, e.g. international trade, based on Odum and Odum (2001)

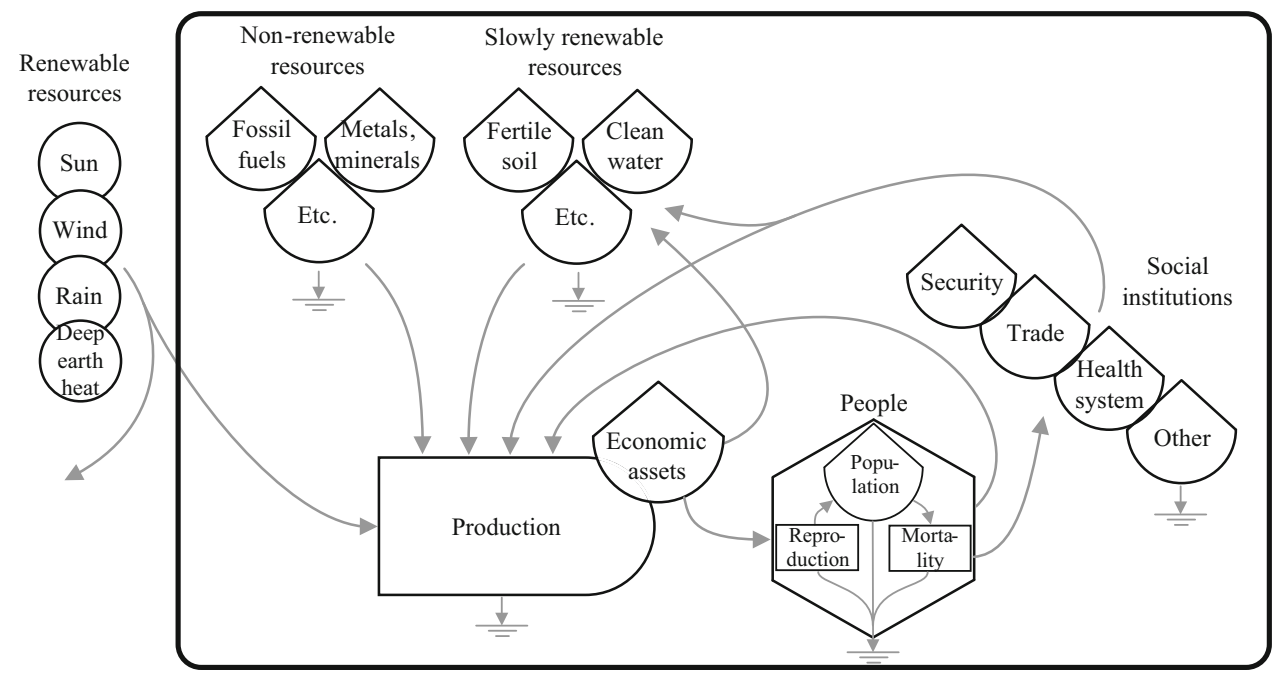


unrest and a tendency for centralisation of power in certain areas, and collapses of the most vulnerable nation states. International trade is maintained by forceful state and corporate influences that are necessary to secure the long supply chains of centralised production. Two important reasons for the failed transition are the underestimation of a consumption-based culture and the popular misunderstanding that renewable energy technologies are sufficient to fully replace modern world energy demands and support continued economic growth. After a series of crises initiated primarily by high commodity prices, and involving political conflicts causing internal strife, military actions to secure vital resources, extreme weather events, and migratory pressures, the global economy moves into a seemingly steady recession.

The Brown Tech narrative envisions lower MSOL, increased resource and labour use per input, lower renewability and increased centralisation reflected in decreased autonomy. The Brown Tech scenario assumes reduced efficiency in production $(200 \%)$ and reduced availability $(150 \%)$ of material and energy inputs, less resource use associated with labour inputs (50\%), lower renewability and local supply fractions (various).

\section{Earth Stewards}

The story of Earth Stewards pictures a harmonic relationship between man and nature in a society that is rebuilt almost from the bottom after a tumultuous transition away from fossil fuels. The narrative takes place after the world has gone through a succession of overwhelming collapses, including failures of nation states, severe economic recession, major conflicts, mass migration, population loss, and breakdown of national and international political institutions and trade. Locally, however, pockets of relative stability are able to develop and prosper, partially from the craftsmanship and entrepreneurial, experimental spirit of individuals and partially from the sudden demand for locally produced goods. In this process, development objectives shift from growth and material wealth to sufficiency and distribution, based on the realisation that environmental balance and social cohesion are the foundations of a sustainable society. In the course of some decades, a culture of local government, permaculture philosophy, low-tech approaches, cooperation and social inclusion spread to include the majority of mankind. In this world of Earth Stewards, the use of non-renewable resources is almost abandoned since trade networks are small and supply chains very short, making centralised production uneconomical. Most production has small net outputs due to resource scarcity and extreme environmental caution.

The Earth Stewards narrative depicts a reduction in MSOL, higher resource use per unit and a fully renewable production. The Earth Stewards scenario assumes reduced efficiency in production of material and energy inputs $(200 \%)$ and reduced availability of those inputs $(200 \%)$, less resource use associated with labour inputs (50\%), and $100 \%$ renewable and local supply.

\section{Lifeboats}

Following an extended, unsuccessful transition away from fossil fuels (as in the Brown Tech narrative), society tumbles into a devastating breakdown, not unlike the succession of collapses described in the Earth Stewards narrative, exacerbated by uncontrollable climatic changes. While single communities in certain well-protected areas are able to pursue a constructive but very slow rebuilding of social, economic and political institutions, the dominating lifestyle is nomadic, hunter-gatherer and characterised by insecurity, famine, disease, grief, violence and no development. Trade is extremely limited and production is inefficient due to the lack of security, necessary knowledge, skills and tools. Most activities are based on renewable resources, since there is close to no access to refined fuels, metals and other industrial society goods apart from those salvageable from abandoned population centres.

The Lifeboats narrative pictures radically reduced MSOL, inefficient production and very low availability of external inputs. Renewability is assumed to increase, since renewable energy inputs will constitute a higher fraction of the economy. The Lifeboats scenario assumes reduced efficiency in production $(300 \%)$ and reduced availability $(500 \%)$ of material and energy inputs, less resource use associated with labour inputs (10\%), higher renewability fractions (various) and entirely local supply.

\section{The Role of Labour Inputs in the Assessment of Biophysical Efficiency}

With the modelling parameters in place as suggested, it is possible to analyse how certain types of production systems will perform in different scenarios. As an example (Fig. 3), we consider systems with different emergy profiles in terms of dependence on on-site renewable (OR) inputs (10 or $70 \%$ of total emergy flow under reference conditions), labour fraction (labour (DL+IL) in \% of total emergy flow under reference conditions), and balance between indirect and direct labour (75 and $25 \%$ or 25 and $75 \%$ of emergy of labour). The remaining emergy flows are supporting inputs of fossil fuels, their derivatives, metals, minerals (NR) and biological material (SR), equally distributed between the two categories. We assume that the output from all systems is the same. Other combinations of OR 
and balance between indirect and direct labour are provided in Fig. 4 (see Appendix).

The extreme emergy profiles, i.e. only $10 \%$ OR and $10 \%$ labour, predominantly IL (shown in Fig. 3a), and $70 \%$ OR and $30 \%$ labour, predominantly DL (shown in Fig. 3b), are useful to consider as archetypes. They are characteristic of production systems that may be referred to as, respectively, "non-renewable and material intensive in a trade network" and "renewable and labour intensive in a local economy". The estimated UEV adjustment factor $\lambda$ applies to the UEV of a given system's output and adjusts for all scenario-specific parameter changes. The UEV factor is relative to the UEV under reference scenario conditions (Eq. (7)).

Two fictive production systems that provide the same output are considered to demonstrate the applicability of the analysis. Production system I is characterised by a UEV of $1.0 \mathrm{E}+05 \mathrm{sej} / \mathrm{J}$ consisting of $10 \% \mathrm{OR}, 80 \%$ emergy flow from other inputs, and $10 \%$ labour of which $75 \%$ is IL (Fig. 3a, far left). Production system II is characterised by a UEV of $1.0 \mathrm{E}+05 \mathrm{sej} / \mathrm{J}$ consisting of $70 \% \mathrm{OR}$ and $30 \%$ labour of which $25 \%$ is IL (Fig. 3b far right). Under current conditions, the two systems are considered to be equally efficient. In a Green Tech scenario, the UEV of

(a) $\quad 10 \%$ OR \& labour is $75 \%$ IL

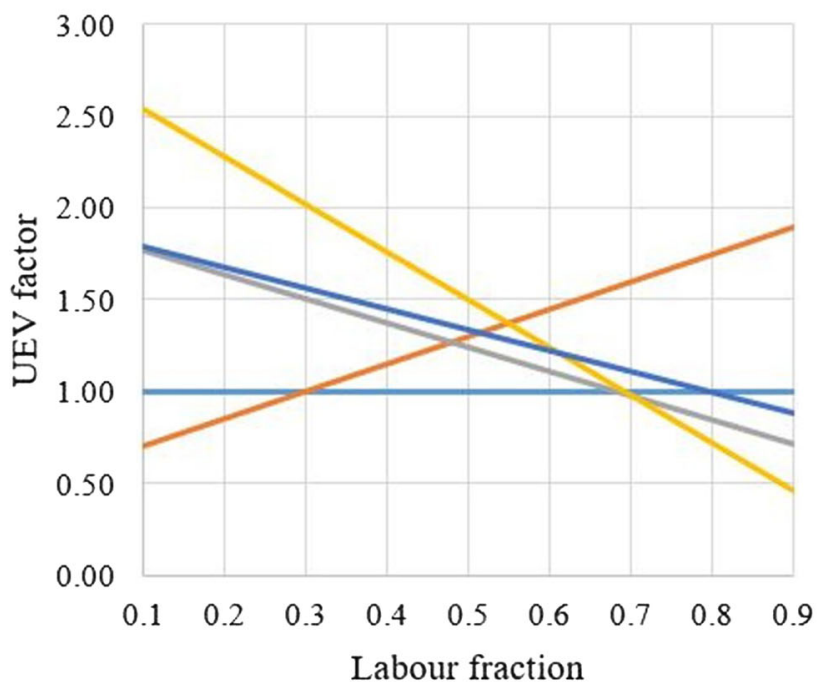

system I is adjusted by a factor 0.70 and the UEV of system II is adjusted by a factor 1.3. The resulting UEVs are $0.7 \mathrm{E}+05$ and $1.3 \mathrm{E}+05 \mathrm{sej} / \mathrm{J}$, respectively. In a Brown Tech scenario, the UEV of system I is adjusted by a factor 1.8 and the UEV of system II is adjusted by a factor 0.9 . The resulting $\mathrm{UEVs}$ are $1.8 \mathrm{E}+05$ and $0.9 \mathrm{E}+05 \mathrm{sej} / \mathrm{J}$, respectively. If the UEV is used to select the production system to prioritise, an expectation of a Green Tech future will point to prioritising system I and an expectation of a Brown Tech future will point to system II. If a lower UEV is indicative of resilience, production system I may be considered resilient in a Green Tech development but less resilient in the other scenarios. Conversely, production system II displays resilience to Brown Tech, Earth Stewards and Lifeboat futures, but not to a Green Tech future.

The analysis shows a consistent picture of scenario significance: UEVs may in some cases be less than half of and in other cases as much as 2.5 times more than UEVs calculated with reference assumptions. The most dramatic changes to UEVs are in the Lifeboats scenario. Using Earth Stewards and Brown Tech assumptions significantly influence UEV results when labour fractions are relatively low, while Green Tech assumptions influence the UEV most when labour fractions are high. Generally, scenario

(b)

$70 \%$ OR \& labour is $25 \%$ IL

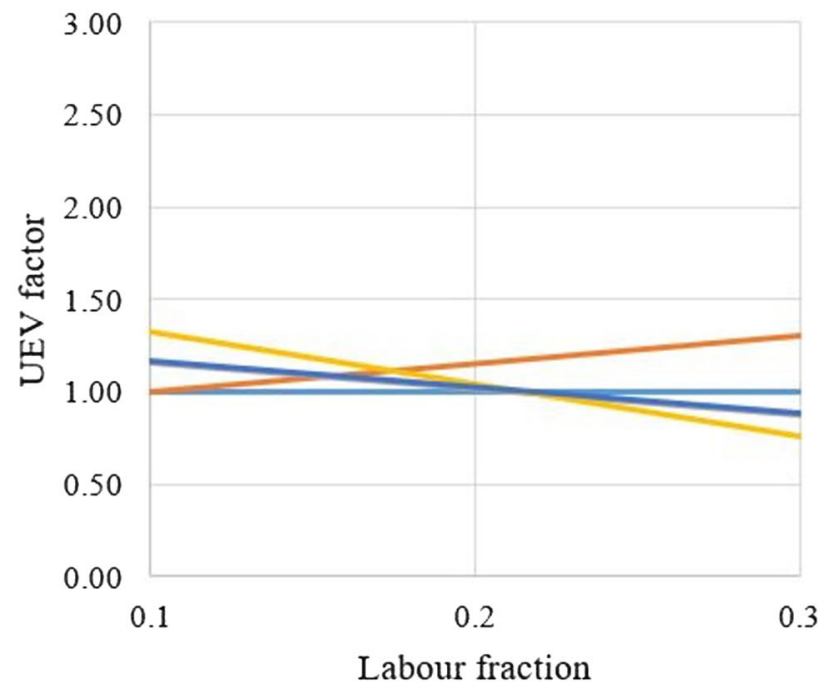

UEV index for current conditions

UEV factor $\lambda$ Green Tech

UEV factor $\lambda$ Brown Tech

$-\mathrm{UEV}$ factor $\lambda$ Lifeboats

UEV factor $\lambda$ Earth Stewards

Fig. 3 UEV adjustment factor $\lambda$ for output of different systems characterised by dependence on (a) $10 \%$ on-site renewable inputs (OR), $75 \%$ of total labour is indirect labour (IL), and (b) $70 \%$ on- site renewable inputs (OR), $25 \%$ of total labour is indirect labour (IL). For the remaining categories see text 
values provide higher UEVs than under reference assumptions, with a couple of exceptions: in Green Tech when labour inputs are small compared to other non-OR inputs and, in the other scenarios, when labour inputs are relatively high compared to other non-OR inputs. A high fraction of on-site, renewable input has a stabilising effect on results. With the suggested scenario assumptions, the balance between direct and indirect labour is not very influential on UEV results. The context of some scenario analyses will support different $\beta_{\mathrm{c}, \mathrm{s}}$ for direct and indirect labour, respectively (i.e. different changes in resource use associated with the two types of labour), increasing the importance of the balance between the two types of labour input.

\section{Discussion}

The characteristics of conceivable, future socio-economic conditions are unknown. We find that it is possible, nevertheless, to improve environmental sustainability assessments by making qualified guesses about changes in the socio-economic conditions which are central to the indicators investigated. We suggest to do this with the use of simplistic narratives and associated parameterisation of chosen indicators related to resilience. The procedure acts as guidance on how to manage uncertainty about future scenarios. Being explicit about the future may be controversial, but modelling as if conditions will not change will surely provide biased results. Explorative scenario analysis is a procedure that opens up the space of possible futures, not with the specific objective of claiming to know unknowable details, but to put forward what is considered to be within the probable. Putting words on some of the challenges that we may encounter will help to prioritise among adaptation strategies.

We regard resource use efficiency and reliance on renewable and local inputs as associated with resilience. In EmA, we are able to categorise inputs as renewable and non-renewable, local and non-local, and to provide a consistent measure of resource use efficiency. This allows for the screening of technologies that can be considered relatively resilient. We do not propose the emergy resilience indicators as substitutes for the very specific resilience indicators found in the literature. For this, they are too rudimentary. We find, however, that the selected foci are useful as a first step in assessment of general resilience.

We carried out an analysis of hypothetical production systems with different characteristics in terms of the dependence on on-site renewable input and labour inputs. The biophysical efficiency was shown to be significantly influenced by the altered parameter values in the scenario analysis. Based on this analysis, prioritisation of technologies that rely on on-site renewable inputs and labour inputs rather than material inputs appears prudent if we expect radical energy descent scenarios. The analysis reveals that, in the pursuit of thermodynamic efficiency, choice of strategy appears dependent on expectations of the future. A strategy to substitute material inputs for labour inputs (i.e. use more materials and less labour) is a good idea from a biophysical efficiency perspective only in a Green Tech scenario. In other scenarios, increasing labour inputs while reducing inputs of non- and slowly renewable resources will reduce overall resource use. This conclusion is in line with an emphasis on resource productivity rather than labour productivity (Hinterberger and Schmidt-Bleek 1999; Møller 2011).

Explorative scenario analysis with the UEV, global renewability and local supply fraction parameter values developed in this paper was recently carried out in a comparison of four food and bioenergy production practices for a village in Ghana (Kamp and Østergård 2016). In that study, reference conditions showed only minor differences between the studied practices. In the scenario analysis, the Green Tech scenario supported business-asusual practice, while the more radical energy descent scenarios supported practices characterised by local, renewable inputs and the recycling of nutrients.

Acknowledgments This research was financially supported by DANIDA through the project "Biofuel production from lignocellulosic materials -2GBIONRG”, DFC journal no. 10-018RIS $\varnothing$.

\section{Compliance with Ethical Standards}

Conflict of interest The authors report no conflict of interest.

\section{Appendix}

See Fig. 4. 

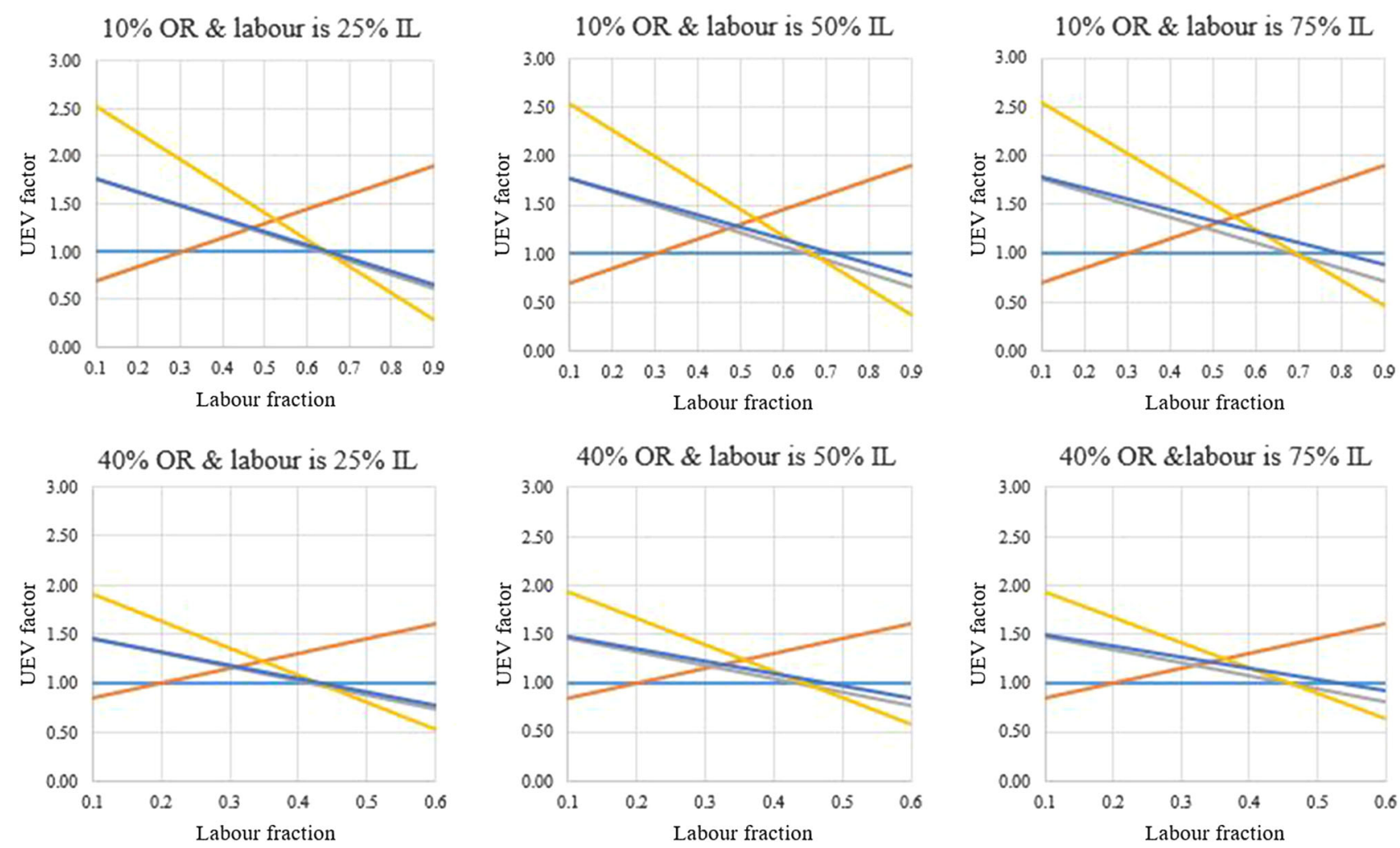

$70 \%$ OR \& labour is $25 \% \mathrm{IL}$
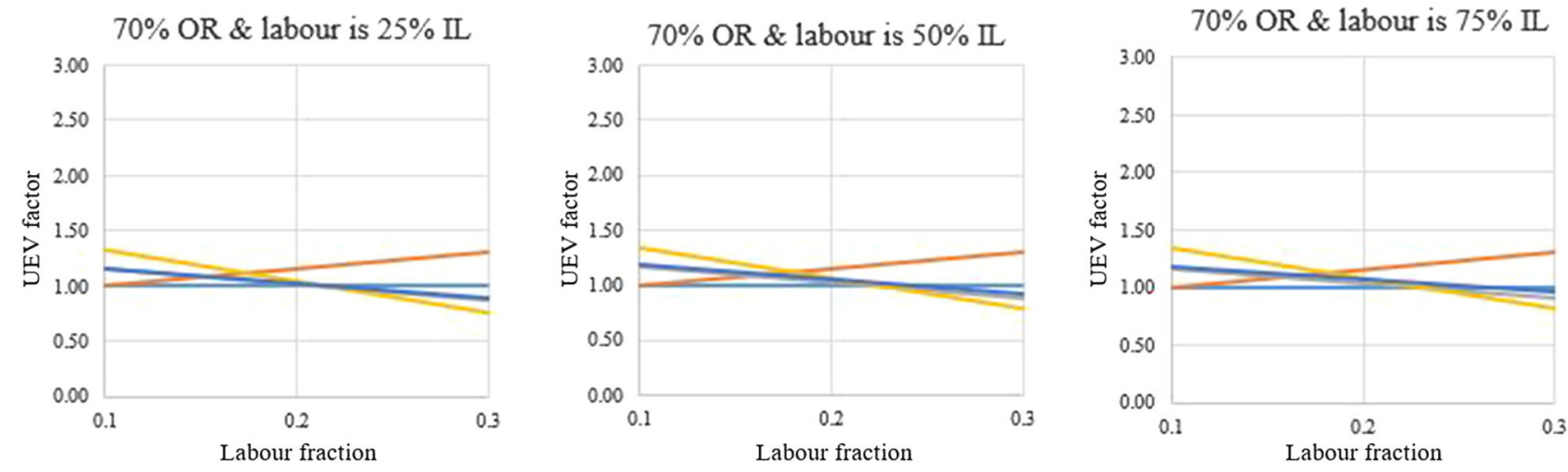

\section{- UEV index for current conditions \\ - UEV factor $\lambda$ Green Tech \\ - UEV factor $\lambda$ Brown Tech \\ - UEV factor $\lambda$ Lifeboats \\ - UEV factor $\lambda$ Earth Stewards}

Fig. 4 UEV adjustment factors in different systems characterised by on-site renewable resources $(10,40,70 \% \mathrm{OR})$, total labour fraction (x-axis) and indirect labour fraction of total labour (25, 50, $75 \%$ IL).

\section{References}

Abel $T$ (2010) Human transformities in a global hierarchy: emergy and scale in the production of people and culture. Ecol Model.I][ 221:2112-2117. doi:10.1016/j.ecolmodel. 2010.05.014
Total inputs sum to $100 \%$ with the remaining emergy flows evenly distributed between the remaining two categories fossil fuels, their derivatives, metals and minerals and biological material
Bennett EM, Cumming GS, Peterson GD (2005) A systems model approach to determining resilience surrogates for case studies. Ecosystems 8:945-957. doi:10.1007/s10021-005-0141-3

Börjeson L, Höjer M, Dreborg K-H et al (2006) Scenario types and techniques: towards a user's guide. Futures 38:723-739. doi:10. 1016/j.futures.2005.12.002 
Brown MT, Ulgiati S (1997) Emergy-based indices and ratios to evaluate sustainability: monitoringeconomies and technology toward environmentally sound innovation. Ecol Eng 9(1-2):51-69. doi:10.1016/S0925-8574(97)00033-5

Brown MT, Ulgiati S (2011) Understanding the global economic crisis: a biophysical perspective. Ecol Model 223:4-13. doi:10. 1016/j.ecolmodel.2011.05.019

Cabel JF, Oelofse M (2012) An indicator framework for assessing agroecosystem resilience. Ecol Soc. doi:10.5751/ES-04666170118

Carpenter S, Walker B, Anderies JM, Abel N (2001) From metaphor to measurement: resilience of what to what? Ecosystems 4:765-781. doi:10.1007/s10021-001-0045-9

Cavalett O, De Queiroz JF, Ortega E (2006) Emergy assessment of integrated production systems of grains, pig and fish in small farms in the South Brazil. Ecol Model 193:205-224. doi:10. 1016/j.ecolmodel.2005.07.023

EC (2010) European Commission-Joint Research Centre-Institute for Environment and Sustainability. International reference life cycle data system (ILCD) Handbook-general guide for life cycle assessment-detailed guidance. Publications Office of the European Union, Luxembourg

Fortes P, Alvarenga A, Seixas J, Rodrigues S (2015) Long-term energy scenarios: bridging the gap between socio-economic storylines and energy modeling. Technol Forecast Soc Change 91:161-178. doi:10.1016/j.techfore.2014.02.006

Franzese PP, Rydberg T, Russo GF, Ulgiati S (2009) Sustainable biomass production: a comparison between gross energy requirement and emergy synthesis methods. Ecol Indic 9:959-970. doi:10.1016/j.ecolind.2008.11.004

Heinberg R (2004) Powerdown-options and actions for a postcarbon world. New Society Publishers, Gabriola Island

Hinterberger F, Schmidt-Bleek F (1999) Dematerialization, MIPS and factor 10 physical sustainability indicators as a social device. Ecol Econ 29:53-56. doi:10.1016/S0921-8009(98)00080-9

Hirsch RL (2008) Mitigation of maximum world oil production: shortage scenarios. Energy Policy 36:881-889. doi:10.1016/j. enpol.2007.11.009

Höjer M, Ahlroth S, Dreborg KH et al (2008) Scenarios in selected tools for environmental systems analysis. J Clean Prod 16:1958-1970. doi:10.1016/j.jclepro.2008.01.008

Holling CS (1986) The resilience of terrestrial ecosystems: local surprise and global change. In: Clark WC, Munn RE (eds) Sustainable development of the biosphere. Cambridge University Press, pp. 292-317

Holmgren D (2009) Future scenarios: how communities can adapt to peak oil and climate change. Chelsea Green Publishing, Vermont

Hopkins R (2006) Energy descent pathways: evaluating potential responses to peak oil. University of Plymouth, Plymouth
IPCC (2014) Climate change 2014: impacts, adaptation and vulnerability. Summary for policy makers

Kamp A, Østergård H (2016) Future scenario modelling and resilience indicators. A case study of small-scale food and energy production in a village in Ghana. In: Brown MT, Sweeney S, Campbell DE, et al. (eds) Submitted to Emergy synthesis 9: Theory and applications of the emergy methodology. Proceedings of the 9th biennial emergy conference, 2016. Center for Environmental Policy, University of Florida, Gainesville, USA. (in press)

Kupers R (ed) (2014) Turbulence. A corporate perspective on collaborating for resilience. Amsterdam University Press, Amsterdam

Lambert JG, Lambert GP (2011) Predicting the psychological response of the American people to oil depletion and declining energy return on investment (EROI). Sustainability 3:2129-2156. doi:10.3390/su3112129

Mohr SH, Wang J, Ellem G et al (2015) Projection of world fossil fuels by country. Fuel 141:120-135. doi:10.1016/j.fuel.2014.10. 030

Møller JØ (2011) Conventional economic theory-a critique highlighting flaws in American style capitalism. Singap Econ Rev 56:1-18. doi:10.1142/S0217590811004067

Nordås R, Gleditsch NP (2007) Climate change and conflict. Polit Geogr 26:12. doi:10.1016/j.polgeo.2007.06.003

Odum HT (1996) Environmental accounting. Emergy and environmental decision making. Wiley, New York

Odum HT, Odum EC (2001) A prosperous way down, 2008th edn. University Press of Colorado, Boulder

Odum HT, Odum EC (2006) The prosperous way down. Energy 31:21-32. doi:10.1016/j.energy.2004.05.012

Schubert R, Schellnhuber HJ, Buchmann N et al (2007) Climate change as a security risk. Earthscan, London

Spielmann M, Scholz R, Tietje O, De Haan P (2005) Scenario modelling in prospective LCA of transport systems. Application of formative scenario analysis (11 pp). Int J Life Cycle Assess 10:325-335. doi:10.1065/lca2004.10.188

Tverberg GE (2012) Oil supply limits and the continuing financial crisis. Energy 37:27-34. doi:10.1016/j.energy.2011.05.049

Ulgiati S, Bargigli S, Raugei M (2005) Dotting the I's and crossing the T's of emergy synthesis: material flows, information and memory aspects, and performance indicators. In: Brown MT, Bardi S, Campbell DE, Comar V, Haung S, Rydberg T, Tilley D, Ulgiati S (eds) Emergy synthesis 3: theory and applications of the emergy methodology: proceedings from the 3rd biennial emergy conference, 2005. Center for Environmental Policy, University of Florida, Gainesville, pp. 199-213

Walker B, Holling CS, Carpenter SR, Kinzig A (2004) Resilience, adaptability and transformability in social-ecological systems. Ecol Soc 9:5. doi:10.1103/PhysRevLett.95.258101 